\title{
Thermodynamically stable lithium silicides and germanides from density-functional theory calculations
}

\author{
Andrew J. Morris*, ${ }^{1}$ C. P. Grey, ${ }^{2}$ and Chris J. Pickard ${ }^{3}$ \\ ${ }^{I}$ Theory of Condensed Matter Group, Cavendish Laboratory, University of Cambridge, \\ J. J. Thomson Avenue, Cambridge CB3 OHE, United Kingdom \\ ${ }^{2}$ Department of Chemistry, University of Cambridge, Lensfield Road, Cambridge CB2 1EW, United Kingdom \\ ${ }^{3}$ Department of Physics and Astronomy, University College London, Gower St, London WC1E 6BT, United Kingdom
}

(Dated: February 26, 2014)

\begin{abstract}
High-throughput density-functional-theory (DFT) calculations have been performed on the Li-Si and Li-Ge systems. Lithiated Si and Ge, including their metastable phases, play an important technological rôle as Liion battery (LIB) anodes. The calculations comprise structural optimisations on crystal structures obtained by swapping atomic species to $\mathrm{Li}-\mathrm{Si}$ and $\mathrm{Li}-\mathrm{Ge}$ from the $\mathrm{X}-\mathrm{Y}$ structures in the International Crystal Structure Database, where $\mathrm{X}=\{\mathrm{Li}, \mathrm{Na}, \mathrm{K}, \mathrm{Rb}, \mathrm{Cs}\}$ and $\mathrm{Y}=\{\mathrm{Si}, \mathrm{Ge}, \mathrm{Sn}, \mathrm{Pb}\}$. To complement this at various Li-Si and Li-Ge stoichiometries, $a b$ initio random structure searching (AIRSS) was also performed. Between the ground-state stoichiometries, including the recently found $\mathrm{Li}_{17} \mathrm{Si}_{4}$ phase, the average voltages were calculated, indicating that germanium may be a safer alternative to silicon anodes in LIB, due to its higher lithium insertion voltage. Calculations predict high-density $\mathrm{Li}_{1} \mathrm{Si}_{1}$ and $\mathrm{Li}_{1} \mathrm{Ge}_{1} P 4 / \mathrm{mmm}$ layered phases which become the ground state above 2.5 and $5 \mathrm{GPa}$ respectively and reveal silicon and germanium's propensity to form dumbbells in the $\mathrm{Li}_{x} \mathrm{Si}, x=2.33-3.25$ stoichiometry range. DFT predicts the stability of the $\mathrm{Li}_{11} \mathrm{Ge}_{6} \mathrm{Cmmm}, \mathrm{Li}_{12} \mathrm{Ge}_{7}$ Pnma and $\mathrm{Li}_{7} \mathrm{Ge}_{3} P 32_{1} 2$ phases and several new $\mathrm{Li}-\mathrm{Ge}$ compounds, with stoichiometries $\mathrm{Li}_{5} \mathrm{Ge}_{2}, \mathrm{Li}_{13} \mathrm{Ge}_{5}, \mathrm{Li}_{8} \mathrm{Ge}_{3}$ and $\mathrm{Li}_{13} \mathrm{Ge}_{4}$.

PACS numbers:
\end{abstract}

\section{INTRODUCTION}

Lithium-ion batteries (LIBs) are the secondary (rechargeable) battery of choice for portable electronic devices due to their high specific energy (energy per unit weight) and energy density (energy per unit volume). LIBs have the highest capacity of all the commercially available battery technologies and are now being deployed in hybrid and all-electric vehicles. $\frac{1}{-}$ There is substantial interest in enhancing the capacity of LIBs, driven by the economic and environmental advantages of increasing the range of electric vehicles, and enabling longer-life portable electronic devices.

Lithium intercalated graphite is the standard LIB negative electrode material due to its good rate capability and cyclability, but demand for even higher performance LIBs has motivated the investigation of other materials. Silicon is an attractive alternative since it has ten times the gravimetric and volumetric capacity of graphite (calculated from the initial mass and volume of silicon) but, unlike graphite, silicon undergoes structural changes on lithiation ${ }^{2-4}$ The negative electrode may be studied using a half-cell containing lithium and silicon. The term "anode" applies to the negative electrode during LIB discharge only, so to avoid confusion we refer to lithiation and delithiation of the silicon half-cell which corresponds to charging and discharging the LIB respectively. The first lithiation of the cell at room temperature involves the conversion of crystalline silicon (c-Si) into an amorphous lithium silicide phase $\left(a-\mathrm{Li}_{y} \mathrm{Si}\right)_{\frac{5}{\underline{5}}}$ The onset of amorphization depends on the lithiation rate and has been measured at

\footnotetext{
*Email: ajm255@cam.ac.uk
}

$y \approx 0.3$ in micron-sized ( 325 mesh) silicon clusters after irreversible SEI (solid-electrolyte interphase) formation has been taken into account ${ }^{6,7}$ Below a discharge voltage of $50 \mathrm{mV}$ the $a-\mathrm{Li}_{y} \mathrm{Si}$ crystallizes to form a metastable $\mathrm{Li}_{15} \mathrm{Si}_{4}$ phase which may become non-stoichiometric, $\mathrm{Li}_{15 \pm \delta} \mathrm{Si}_{4}$, at deep discharge .6 However, at temperatures above $100^{\circ} \mathrm{C}$ it is possible to form the most lithiated crystalline phase, $\mathrm{Li}_{21} \mathrm{Si}_{5}$, electrochemically.$\stackrel{8}{*}$ Full lithiation of silicon leads to a drastic volume expansion of $270-280 \%, \underline{9}$ which generates considerable mechanical stress. Hysteresis in the capacity/voltage profile occurs due to a combination of mechanical stress and different reactions taking different structural pathways on lithiation and delithiation. The microscopic mechanisms underlying these phenomena are still not entirely clear. ${ }^{9} a-\mathrm{Li}_{y} \mathrm{Si}$ has been studied in situ using nuclear magnetic resonance

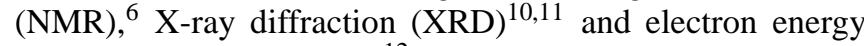
loss spectroscopy (EELS). $\stackrel{12}{ }$ These studies along with ex situ NMR and PDF (pair-distribution function) studies of XRD data suggest that silicon forms small clusters and isolated atoms during lithiation. The clusters that form only break apart into isolated silicon atoms at the end of the lithiation process (below $80 \mathrm{mV}$ ) $! \underline{13}$

Many of the disordered structures that form during lithiation can be approximated by the $\mathrm{Li}-\mathrm{Si}$ ground-state and metastable crystalline phases. For instance, the crystalline phases have been used as a first step in understanding charge transfer $\frac{17}{17}$ and average lithiation voltages ${ }^{45}$ To gain insight into the possible types of silicon clusters present and their environments in $a-\mathrm{Li}_{y} \mathrm{Si}$, various crystalline phases have been investigated and categorized using $\mathrm{NMR}^{6.14}$ and $a b$ initio theoretical techniques. ${ }^{15-18}$ These $c$-Li-Si phases have previously been well categorized using density-functional the-

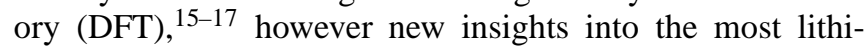


ated phases and the ability to synthesize $\mathrm{Li}_{1} \mathrm{Si}_{1}$ through ball milling have suggested that the system is far from fully understood. The most recent phase diagram of the Li-Si system shows, in ascending lithium content order, $c-\mathrm{Si}, \mathrm{Li}_{1} \mathrm{Si}_{1}$, $\mathrm{Li}_{12} \mathrm{Si}_{7}, \mathrm{Li}_{7} \mathrm{Si}_{3}, \mathrm{Li}_{13} \mathrm{Si}_{4}, \mathrm{Li}_{15} \mathrm{Si}_{4}, \mathrm{Li}_{22} \mathrm{Si}_{5}$, and $\beta$-Li ${ }^{19}$ Additionally investigations by Zeilinger and coworkers have presented a high-temperature $\mathrm{Li}_{4.11} \mathrm{Si}$ phase $\frac{18,20}{}$ and suggested $\mathrm{Li}_{17} \mathrm{Si}_{4}$ as the correct stoichiometry of $\mathrm{Li}_{21} \mathrm{Si}_{5} / \mathrm{Li}_{22} \mathrm{Si}_{5}$.

Germanium is another choice of anode for LIB with a theoretical capacity of $1568 \mathrm{mAh} \mathrm{g}^{-1}$ some 5 times greater than carbon. Its lithium diffusivity at room temperature is 400 times greater than silicon, 21 however it is scarcer and consequently more expensive. About the Li-Ge phase diagram, much less is known. In increasing order of lithium content, the following stable phases have all been proposed: $\mathrm{Li}_{7} \mathrm{Ge}_{12}, \frac{22}{2}$

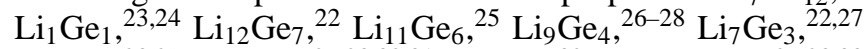

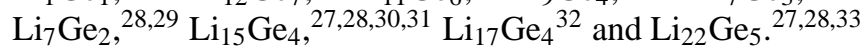
More crystalline phases occur during electrochemical lithiation of germanium than silicon; XRD and HRTEM measurements show that during lithiation of germanium at room temperature, the $\mathrm{Li}-\mathrm{Ge}$ system progressed through $\mathrm{Li}_{9} \mathrm{Ge}_{4}$, $\mathrm{Li}_{7} \mathrm{Ge}_{2}$ and a mixture of $\mathrm{Li}_{15} \mathrm{Ge}_{4}$ and $\mathrm{Li}_{22} \mathrm{Ge}_{5} \stackrel{28}{\underline{2}}$

In this article we use atomic species swapping along with random structure searching techniques, described in Sec.II to predict ground state and metastable crystal structures of the $\mathrm{Li}-\mathrm{Si}$ and and $\mathrm{Li}-\mathrm{Ge}$ systems. In Sec.III our approach to calculating average voltages is discussed and Secs[V and $\mathrm{V}$ describe the DFT-predicted phases of Li-Si and Li-Ge respectively. In the Li-Si system we predict a high-density $\mathrm{Li}_{1} \mathrm{Si}_{1}$ phase with $P 4 / \mathrm{mmm}$ symmetry and discuss the tendency for silicon to form dumbbells within the lithium silicides. We then turn our attention to Li-Ge which has not been analyzed using these computational search methods method before and predict the new structures, $\mathrm{Li}_{5} \mathrm{Ge}_{2}, \mathrm{Li}_{13} \mathrm{Ge}_{5}, \mathrm{Li}_{8} \mathrm{Ge}_{3}$ and $\mathrm{Li}_{13} \mathrm{Ge}_{4}$. The average voltages for the $\mathrm{Li}-\mathrm{Si}$ and $\mathrm{Li}-\mathrm{Ge}$ systems are presented including the $\mathrm{Li}_{17} \mathrm{Si}_{4}$ and $\mathrm{Li}_{1} \mathrm{Si}_{1}$ phases. The conclusions of the simulations are given in Sec.VI

\section{METHODS}

$A b$ initio random structure searching (AIRSS) has been successful in predicting the ground-state structures of highpressure phases of matter 34.35 More recently is has also been applied to the Li-P system ${ }^{36}$ and defects in technologically relevant ceramics, $, 37,38$ semiconductors 39,40 and LIBs $:{ }^{41.42}$ Since in an AIRSS calculation each random starting configuration is independent from another, the search algorithm is trivially parallelisable, making high-throughput computation straightforward. AIRSS searches were performed for stoichiometries $\mathrm{Li}_{x} \mathrm{Si}_{y}$ and $\mathrm{Li}_{x} \mathrm{Ge}_{y}$ where $x, y=1-8$.

Relaxations were performed using the stoichiometric crystal structures of Li-Si, Li-Ge, Li-Sn, Li-Pb, Na-Si, Na-Ge, $\mathrm{Na}-\mathrm{Sn}, \mathrm{Na}-\mathrm{Pb}, \mathrm{K}-\mathrm{Si}, \mathrm{K}-\mathrm{Ge}, \mathrm{K}-\mathrm{Sn}$ and K-Pb. First, the structures were obtained from the International Crystallographic Structure Database (ICSD). Second, for each structure the anions were replaced with $\mathrm{Li}$ and the cations replaced with $\{\mathrm{Si}, \mathrm{Ge}\}$. The structures were relaxed to local-energy minima using forces and stresses calculated by DFT.

Calculations were performed using the plane wave CASTEP DFT code. $\stackrel{43}{ }$ The PBE (Perdew-Burke-Ernzerhof) exchangecorrelation functional was used with Vanderbilt "ultrasoft" pseudopotentials. The $\mathrm{Li}-\mathrm{Si}$ system required a basis set containing plane waves with energies of up to $400 \mathrm{eV}$ and a Monkhorst-Pack (MP) grid corresponding to a Brillouin zone (BZ) sampling grid finer than $2 \pi \times 0.05 \AA^{-1}$. The Li-Ge system required a $600 \mathrm{eV}$ planewave cutoff with harder pseudopotentials and a BZ sampling finer than $2 \pi \times 0.03 \AA^{-1}$.

We define the formation energy per atom of a compound $\operatorname{Li}_{m} \mathrm{X}_{n}$, where $X=\{\mathrm{Si}, \mathrm{Ge}\}$ as,

$$
E_{f} / A=\frac{E\left(\mathrm{Li}_{n} \mathrm{X}_{m}\right)-n \mu_{\mathrm{Li}}-m \mu_{\mathrm{X}}}{n+m},
$$

where $E\left(\mathrm{Li}_{n} \mathrm{X}_{m}\right)$ is the total DFT energy of a given structure, $\mathrm{Li}_{n} \mathrm{X}_{m}$ and $\mu_{\mathrm{Li}}$ and $\mu_{\mathrm{X}}$ are the chemical potentials of atomic species $\mathrm{Li}$ and $\mathrm{X}$ in their ground state elemental structure. To compare the stabilities of different stoichiometries we plot the formation energy per atom, $E_{f} / A$ versus the fractional concentration of lithium in a compound where,

$$
C_{\mathrm{Li}}=\frac{n}{n+m},
$$

and, as above, $n$ and $m$ are the number of atoms of $\mathrm{Li}$ and $\mathrm{X}$ in a compound respectively. Drawing a convex hull from $\left(C_{\mathrm{Li}}, E_{f} / A\right)=(0,0)$ to $(1,0)$, that is, between the chemical potentials, reveals the stable zero Kelvin structures at the vertices of the tie-lines.

\section{VOLTAGES}

We calculate average voltages in an LIB anode using DFT total energies by assuming that all the displaced charge is due to $\mathrm{Li}$ and that the reaction proceeds sequentially through the phases on the tie-lines of the convex hull, i.e. it is a succession of two-phase reactions. ${ }^{44}$ The voltage is given by,

$$
V=-\frac{\Delta G}{\Delta x}
$$

where the Gibbs free energy change, $\Delta G$ is in $\mathrm{eV}$ and $\Delta x$ is the change in the number of lithium atoms per silicon atoms in the 2 phases. The Gibbs free energy is composed of a number of terms,

$$
\Delta G=\Delta E+P \Delta V-T \Delta S,
$$

where $\Delta E$ is the total electronic energy, and $P, \Delta V, T$ and $\Delta S$ are the pressure, change in volume, thermodynamic temperature and change in entropy respectively. Due to the difficulty in calculating $\Delta G$ we make the approximation, previously applied to the Li-Si system, that $\Delta G \approx \Delta E$ since $\Delta E$ is of the order of a few electron volts, $P \Delta V \approx 10^{-5} \mathrm{eV}$ and $T \Delta S \approx 0.06$ $\mathrm{eV}$ at $425^{\circ} C^{45-47}$ 


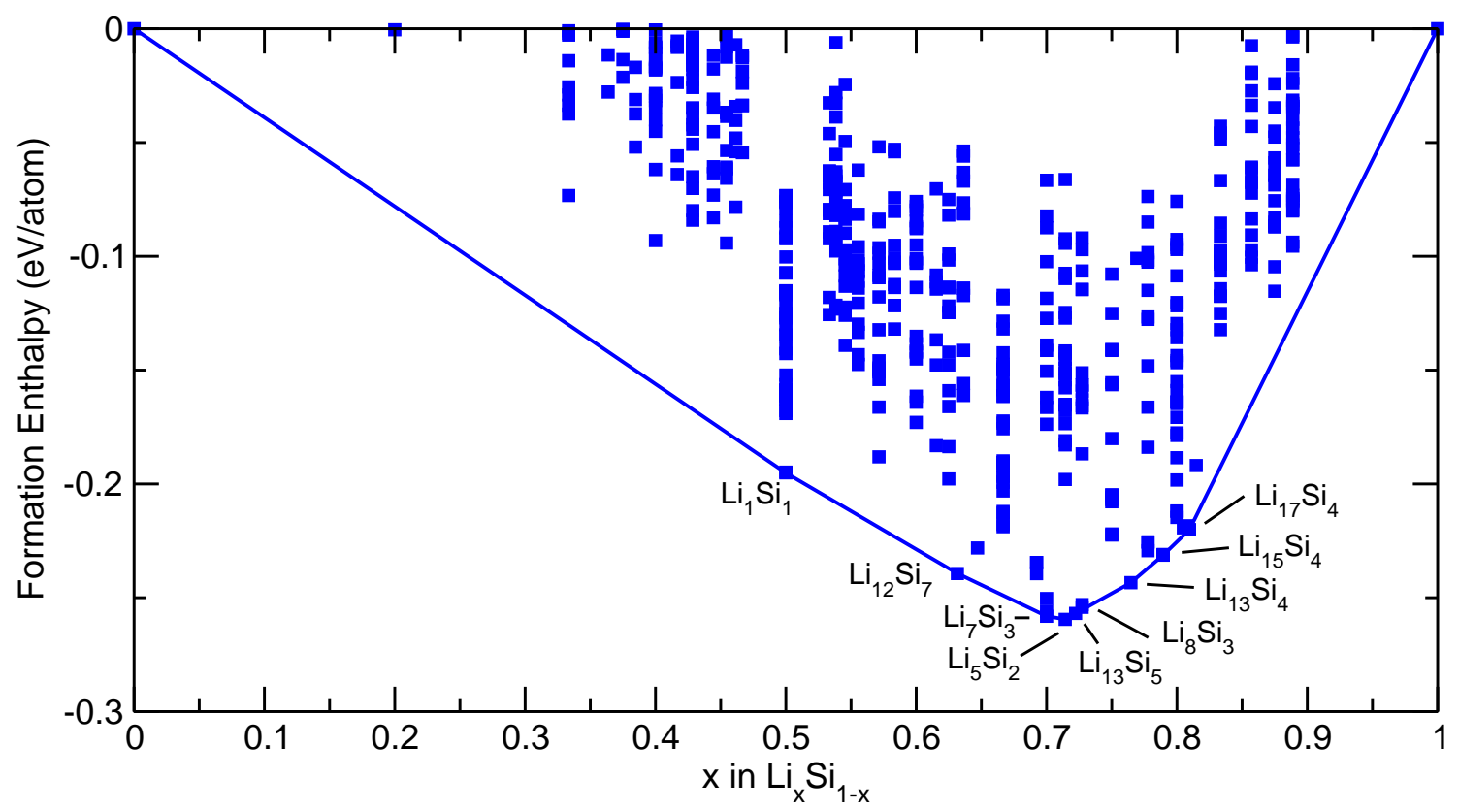

FIG. 1: (Color online) Formation enthalpy per atom versus the fractional lithium concentration of a Li-Si compound (blue boxes). The tie-line (blue line) shows the convex-hull obtained by joining together the globally stable structures predicted by DFT. Between the species swapping technique and AIRSS we recover the known stable phases, $\mathrm{Li}_{1} \mathrm{Si}_{1}, \mathrm{Li}_{12} \mathrm{Si}_{7}, \mathrm{Li}_{7} \mathrm{Si}_{3}, \mathrm{Li}_{13} \mathrm{Si}_{4}, \mathrm{Li}_{15} \mathrm{Si}_{4}$ and $\mathrm{Li}_{17} \mathrm{Si}_{4}$. The searches also find the

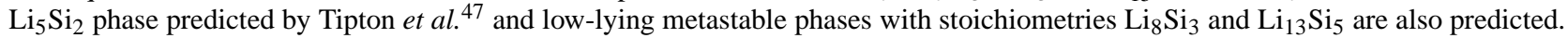

\section{RESULTS - LITHIUM SILICIDE}

We find on the convex hull, shown Fig.1, in increasing lithium content order; diamond-structure $F d \overline{3} m c$-Si; the $I 4_{1} / a \mathrm{Li}_{1} \mathrm{Si}_{1}$ phase ${ }^{48,49}$ which has recently been synthesized at ambient pressure ${ }^{50}$ and is discussed in Sec.IVA, the Pnma $\mathrm{Li}_{12} \mathrm{Si}_{7}$ phase ${ }^{51}$ which contains silicon 5-membered rings and 4-membered stars, which have been studied using NMR; 14 the $\mathrm{Li}_{7} \mathrm{Si}_{3}$ and $\mathrm{Li}_{5} \mathrm{Si}_{2}$ phases with $P 3_{2} 12$ and $R \overline{3} m$ symmetries respectively discussed further in Sec.IVB, the Pbam $\mathrm{Li}_{13} \mathrm{Si}_{4}$ phase; the metastable $I 4 \overline{3} d \mathrm{Li}_{15} \mathrm{Si}_{4}$; and the $\mathrm{Li}_{17} \mathrm{Si}_{4} F \overline{4} 3 m$ symmetry phase discussed further in Sec.IVC.

For $\mathrm{Li}_{15} \mathrm{Si}_{4}$, Mulikan analysis yields a charge of $0.15|e|$ and $-0.57|e|$ per Li and Si respectively; in agreement with Bader analysis that $\mathrm{Li}$ is a cation ${ }^{17}$ and contrary to the reports that $\mathrm{Li}$ is anionic. 52

The average voltage was calculated between all adjacent pairs of stable Li-Si phases on the convex hull including both the $\mathrm{Li}_{17} \mathrm{Si}_{4}$ phase and $\mathrm{Li}_{1} \mathrm{Si}_{1}$ phase recently synthesized at ambient pressure. Voltages were obtained from the DFT total energies, as described in Sec.III and referenced to lithium metal. The potential composition curve is presented in Fig 3 as is in agreement with previous experimental and theoretical work.

\section{A. $\quad \mathbf{L i}_{1} \mathbf{S i}_{1}$ layered structures}

We find a set of structures with $\mathrm{Li}_{1} \mathrm{Si}_{1}$ stoichiometry, listed in Table $\llbracket$ all within $\sim 0.1 \mathrm{eV} / \mathrm{f}$.u. of the ground state. The
DFT ground state at $0 \mathrm{GPa}$ is a $I 4_{1} / a$ phase comprising a 3fold coordinated silicon network hosting lithium tetrahedra similar to the $\{4 \mathrm{Li}, V\}$ Zintl defect in silicon. ${ }^{42}$ Recently the $I 4_{1} / a$ phase has been synthesized via ball-milling and shown to be stable under ambient conditions ${ }^{50}$ Mulikan analysis yields a charge of $0.34|e|$ for each $\mathrm{Li}$ and $-0.34|e|$ for each $\mathrm{Si}$ establishing $\mathrm{Li}$ as cationic contrary to a previous analysis. 49

DFT predicts a novel $P 4 / \mathrm{mmm}$ phase with a formation energy of $0.07 \mathrm{eV}$ p.f.u. at $0 \mathrm{GPa}$. It is a layered structure comprising a two-dimensional (non-tetrahedrally) four-fold coordinated silicon lattice with lithium intercalated between the silicon sheets. Since the silicon is four-fold coordinated it gains less of the lithium's charge than in the $I 4_{1} / a$ phase; $\mathrm{Mu}$ likan analysis shows lithium atoms donate $0.22|e|$ each. Our calculations show the $\mathrm{Li}_{1} \mathrm{Si}_{1}$ system undergoes a phase transition from the $I 4_{1} / a$ to the $P 4 / \mathrm{mmm}$ phase at $2.5 \mathrm{GPa}$.

The $I 4_{1} /$ amd phase is isostructural to its $\mathrm{Li}_{1} \mathrm{Ge}_{1}$ analogue. $\mathrm{Li}_{1} \mathrm{Ge}_{1} \mathrm{I}_{1} /$ amd is stable at high pressure, ${ }^{24}$ however $\mathrm{Li}_{1} \mathrm{Si}_{1}$ $I 4_{1} /$ amd is not globally stable over the pressure range we studied (between 0 and $10 \mathrm{GPa}$ ).

The $P \overline{3} m 1$ phase contains 6 membered rings of 3 -fold coordinated silicon atoms in layered sheets, see Fig 2, The silicon network is isostructural to silicene, a silicon analogue of graphene. We calculate that silicene and a phase based on the $P 4 / \mathrm{mmm}$ silicon network are 0.63 and $0.89 \mathrm{eV}$ p.f.u. respectively above the $F d \overline{3} m$ ground state. When lithiated both layered structures are only $0.07 \mathrm{eV}$ above the $\left(I 4_{1} / a\right)$ ground state. Given the interest in silicene our layered compounds might provide an alternative route to layered silicon. 
TABLE I: Low-energy $\mathrm{Li}_{1} \mathrm{Si}_{1}$ metastable phases. The structures are shown in Fig.2 2 with formation energy $E_{f}$ per formula unit relative to the energy of the ground states. We calculate that $P 4 / \mathrm{mmm}$ is the most stable above $2.5 \mathrm{GPa}$.

\begin{tabular}{cccc}
\hline \hline $\begin{array}{c}\mathrm{E}_{f} \\
(\mathrm{eV} / \text { f.u. })\end{array}$ & Symmetry & $\begin{array}{c}\text { Volume } \\
\left(\AA^{3} / \text { f.u. }\right)\end{array}$ & Description \\
\hline 0.00 & $I 4_{1} / a$ & 31.3 & Li tetrahedra in a 3-fold coordinated Si network \\
0.05 & $R \overline{3}$ & 33.1 & Distorted Li octahedra 3-fold coordinated Si network \\
0.07 & $P 4 / m m m$ & 27.8 & Flat Si sheets comprising 4 membered rings \\
0.07 & $P \overline{1}$ & 31.7 & Buckled Si sheets comprising 8 and 4 membered rings \\
0.07 & $P \overline{3} m 1$ & 34.1 & Li intercalated silicene \\
0.08 & $P 2 / m$ & 28.1 & $\mathrm{Li}_{1} \mathrm{Sn}_{1}$-like 2.39 $\AA$ dumbbells and isolated atoms \\
0.11 & $I 4_{1} /$ amd & 28.1 & Isostructural with $\mathrm{Li}_{1} \mathrm{Ge}_{1}$ high-pressure phase \\
\hline \hline
\end{tabular}

\section{B. $\quad \mathbf{L i}_{7} \mathbf{S i}_{3}$ and $\mathbf{L i}_{5} \mathbf{S i}_{2}$}

Lithium's position in the crystal lattice can be difficult to establish due to its low XRD scattering factor. Furthermore, $\mathrm{Li}_{7} \mathrm{Si}_{3}$ has partially occupied lattice sites ${ }^{53}$ making it difficult to model using DFT. Its structure may be represented as a supercell of $R \overline{3} m \mathrm{Li}_{5} \mathrm{Si}_{2}$ in which lithium atoms have been removed from certain lattice sites. ${ }^{54}$ By choosing different combinations of lithium sites in the supercell, models of $\mathrm{Li}_{7} \mathrm{Si}_{3}$ can be produced with $P \overline{3} \mathrm{~m} 1, C 2 / \mathrm{m} \mathrm{Cm}$ and $P 3_{2} 12$ symmetries. The latter, labeled “\#2" by Dahn et al., 17 is found on the convex hull.

It is unsurprising that at zero Kelvin, DFT also predicts that the $R \overline{3} m \mathrm{Li}_{5} \mathrm{Si}_{2}$ phase to be stable since it contains entirely occupied lithium sites. Tipton et al. also found this phase to be stable using DFT: ${ }^{47}$

\section{Most lithiated phases}

The most lithiated stable Li-Si phase has been the subject of debate. XRD measurements predict that $\mathrm{Li}_{21} \mathrm{Si}_{5}{ }^{55}$ is stable at room temperature and $\mathrm{Li}_{22} \mathrm{Si}_{5}$ at $415^{\circ} \mathrm{C}^{3}$. Previous DFT calculations predict $\mathrm{Li}_{21} \mathrm{Si}_{5}$ to be the stabler phase, even after the inclusion of temperature dependence using the harmonic approximation. ${ }^{17}$ The combined AIRSS/speciesswapping technique predicts $\mathrm{Li}_{21} \mathrm{Si}_{5}$ and $\mathrm{Li}_{22} \mathrm{Si}_{5}$ to be locally stable but above the convex hull. The $\mathrm{Li}_{17} \mathrm{Si}_{4}$ phase is on the convex hull, and it has the same crystal structure as $F \overline{4} 3 m$ $\mathrm{Li}_{17} \mathrm{~Pb}_{4}$, as discovered independently by Zeilinger et al. ${ }^{18}$ Zeilinger et al.also predict a $\mathrm{Li}_{4.11} \mathrm{Si}$ high-temperature phase which they model using $\mathrm{Li}_{16} \mathrm{Si}_{4}$ and $\mathrm{Li}_{16.5} \mathrm{Si}_{4}$ phases. We include Zeilinger et al.'s models in Fig. 1 1 although DFT predicts that they are not on the tie-line. ${ }^{72}$

\section{Repeating units - Silicon dumbbells}

We also find a $R \overline{3} m \mathrm{Li}_{8} \mathrm{Si}_{3}$ and a $P \overline{3} m 1 \mathrm{Li}_{13} \mathrm{Si}_{4}$ phase close above the tie-line. They belong to the set of structures in the range $\mathrm{Li}_{7} \mathrm{Si}_{3} \rightarrow \mathrm{Li}_{13} \mathrm{Si}_{5}$ which all contain silicon dumbbells. The dumbbells are aligned in parallel with various numbers of collinear lithium atoms between them forming one-
TABLE II: Structures in the stoichiometry range $\mathrm{Li}_{x} \mathrm{Si}, x=2.33-$ 2.60 exhibit parallel silicon dumbbells situated in one-dimensional linear columns containing variable numbers silicon dumbbells and isolated lithium and silicon atoms. The columns are packed together realizing the three-dimensional structure. The repeating unit(s) in each column are represented between parentheses, and silicon dumbbells are indicated by Si-Si. For example, a structure comprising columns containing a repeating unit of 5 lithium atoms followed by a silicon dumbbell is represented as $(5 \times \mathrm{Li}+\mathrm{Si}-\mathrm{Si})$.

\begin{tabular}{lc}
\hline \hline Stoichiometry & Constituent columns \\
\hline $\mathrm{Li}_{7} \mathrm{Si}_{3}$ & $2 \times(5 \times \mathrm{Li}+\mathrm{Si}-\mathrm{Si}) \&$ \\
& $(4 \times \mathrm{Li}+\mathrm{Si}-\mathrm{Si})$ \\
$\mathrm{Li}_{5} \mathrm{Si}_{2}$ & $(5 \times \mathrm{Li}+\mathrm{Si}-\mathrm{Si})$ \\
$\mathrm{Li}_{13} \mathrm{Si}_{5}$ & $(5 \times \mathrm{Li}+\mathrm{Si}) \&$ \\
& $2 \times(4 \times \mathrm{Li}+\mathrm{Si}-\mathrm{Si})$ \\
$\mathrm{Li}_{8} \mathrm{Si}_{3}$ & $(4 \times \mathrm{Li}+\mathrm{Si}+4 \times \mathrm{Li}+\mathrm{Si}-\mathrm{Si})$ \\
\hline \hline
\end{tabular}

dimensional repeating sequences, see Table The 1D linear repeating chains are thus packed alongside each other realizing the three-dimensional structure. For example, since $\mathrm{Li}_{7} \mathrm{Si}_{3}$ comprises $(5 \times \mathrm{Li}+\mathrm{Si}-\mathrm{Si})$ and $(4 \times \mathrm{Li}+\mathrm{Si}-\mathrm{Si})$ sequences in a ratio of $2: 1$, it is equivalent to the $\mathrm{Li}_{5} \mathrm{Si}_{2}$ phase with lithium vacancies. $\mathrm{Li}_{5} \mathrm{Si}_{2}$ comprises sequences of atoms with the repeating unit $(5 \times \mathrm{Li}+\mathrm{Si}-\mathrm{Si})$ and the $\mathrm{Li}_{8} \mathrm{Si}_{3}$ is similar but with atoms in a $(4 \times \mathrm{Li}+\mathrm{Si}+4 \times \mathrm{Li}+\mathrm{Si}-\mathrm{Si})$ repeating unit; it is isostructural with a $\mathrm{Li}_{8} \mathrm{~Pb}_{3}$ phase. ${ }^{56}$ The $\mathrm{Li}_{13} \mathrm{Si}_{5}$ phase is isostructural with the $\mathrm{Li}_{13} \mathrm{Sn}_{5}$ phase ${ }^{57}$ and has two different repeating units $(5 \times \mathrm{Li}+\mathrm{Si})$ and $(4 \times \mathrm{Li}+\mathrm{Si}-\mathrm{Si})$ in a ratio of $1: 2$.

Finally, in $\mathrm{Li}_{13} \mathrm{Si}_{4}$ the one-dimensional columnar structure does not exist but $\mathrm{Si}$-Si dumbbells and $\mathrm{Si}$ isolated atoms remain in a ratio of $1: 1$. At higher lithium concentrations, $\mathrm{Li}_{15} \mathrm{Si}_{4}$ forms, in which all silicon dumbbells are broken, and only isolated $\mathrm{Si}$ atoms remain. The propensity for silicon dumbbells to form over a wide range of stoichiometries and total energies implies that silicon dumbbells form on lithiation of silicon in a LIB anode. 


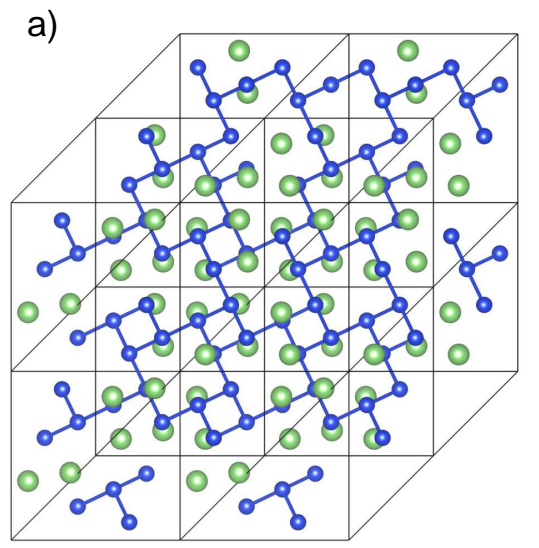

b)

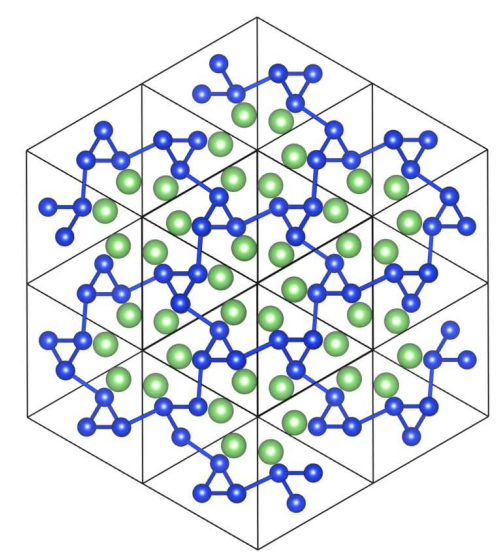

c)

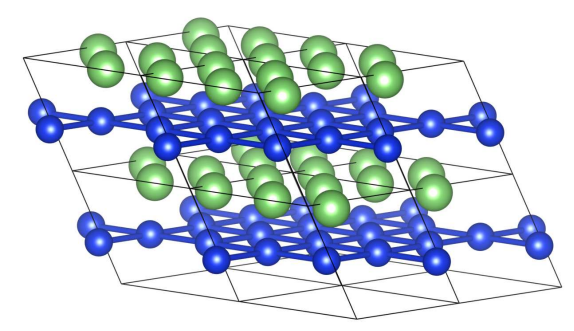

d)

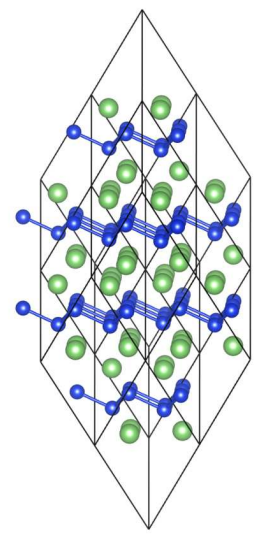

e)

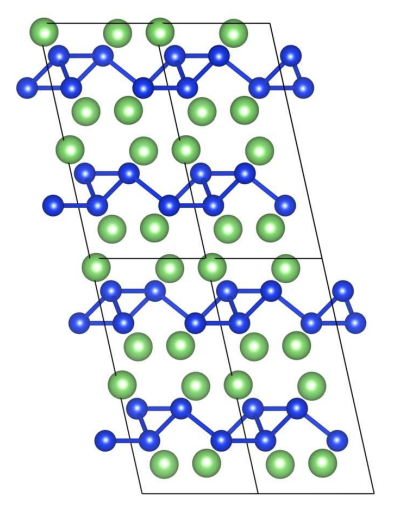

FIG. 2: (Color online) Low-energy $\mathrm{Li}_{1} \mathrm{Si}_{1}$ phases detailed in Table【 with a) $I 4_{1} / a$, b) $R \overline{3}$, c) $P 4 / m m m$, d) $P \overline{3} m 1$, e) $P \overline{1}$ symmetries. DFT predicts the $P 4 / \mathrm{mmm}$ phase to be stable above $2.5 \mathrm{GPa}$.

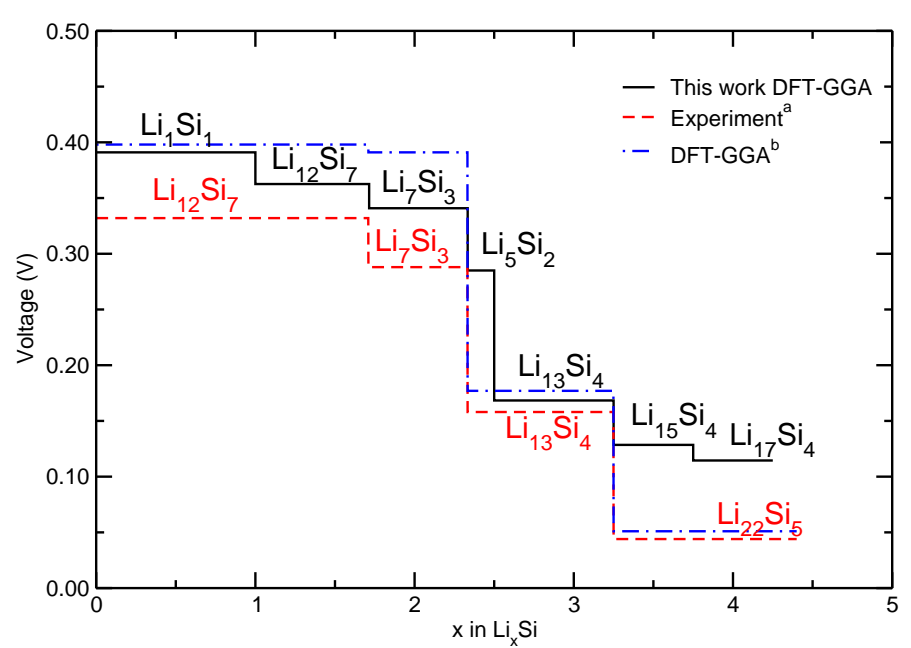

${ }^{a}$ Wen and Huggins ${ }^{3}$

${ }^{b}$ Chevrier et al ${ }^{45}$

FIG. 3: (Color online) Potential-composition curves of stable structures found on the convex hull in Fig.1 (black line) compared to experiment at $415^{\circ} \mathrm{C}$ (red dashed line) and previous DFT-GGA calculations (blue dot-dashed line) ${ }^{45}$

\section{RESULTS - LITHIUM GERMANIDE}

In order of lithium content, the following $\mathrm{Li}-\mathrm{Ge}$ phases have all been proposed: $\mathrm{Li}_{7} \mathrm{Ge}_{12}, \mathrm{Li}_{1} \mathrm{Ge}_{1}, \mathrm{Li}_{12} \mathrm{Ge}_{7}, \mathrm{Li}_{11} \mathrm{Ge}_{6}$, $\mathrm{Li}_{9} \mathrm{Ge}_{4}, \mathrm{Li}_{7} \mathrm{Ge}_{3}, \mathrm{Li}_{7} \mathrm{Ge}_{2}, \mathrm{Li}_{15} \mathrm{Ge}_{4}, \mathrm{Li}_{17} \mathrm{Ge}_{4}$ and $\mathrm{Li}_{22} \mathrm{Ge}_{5}$. Below we compare in detail the known phases to the results of the DFT searches.

$\mathrm{Li}_{7} \mathrm{Ge}_{12}$ is the only reported phase with a ratio of $\mathrm{Li} / \mathrm{Ge}$ less than 1 . It has two symmetries associated with it, originally $P m n 2_{1} 22.60$, which was later disputed, $\stackrel{58}{ }$ and more recently, $P 2 / n \stackrel{61}{ }$ Four of its lithium lattice sites are $50 \%$ occupied. We model its structure in a periodic lattice using a simulation cell containing $28 \mathrm{Li}$ and $48 \mathrm{Ge}$ sites. The fractionally occupied sites can be filled in a variety of ways: all sites, giving rise to a crystal symmetry $P 2 / c$ : one site $(P 1)$, four different ways (all degenerate): two sites, 6 ways $(P c, P 2$ or $P \overline{1})$ each symmetry being doubly degenerate): three sites $(P 1)$ four ways (all degenerate): and by leaving all empty $(P 2 / c)$ one way. A convex hull of their single point energies shows that the $(P c)$ version is the most stable, hence we use this throughout the rest of the calculations. Although not on the Li-Ge convex hull, see Fig. 4] this $P c$ predicted phase is close above. 


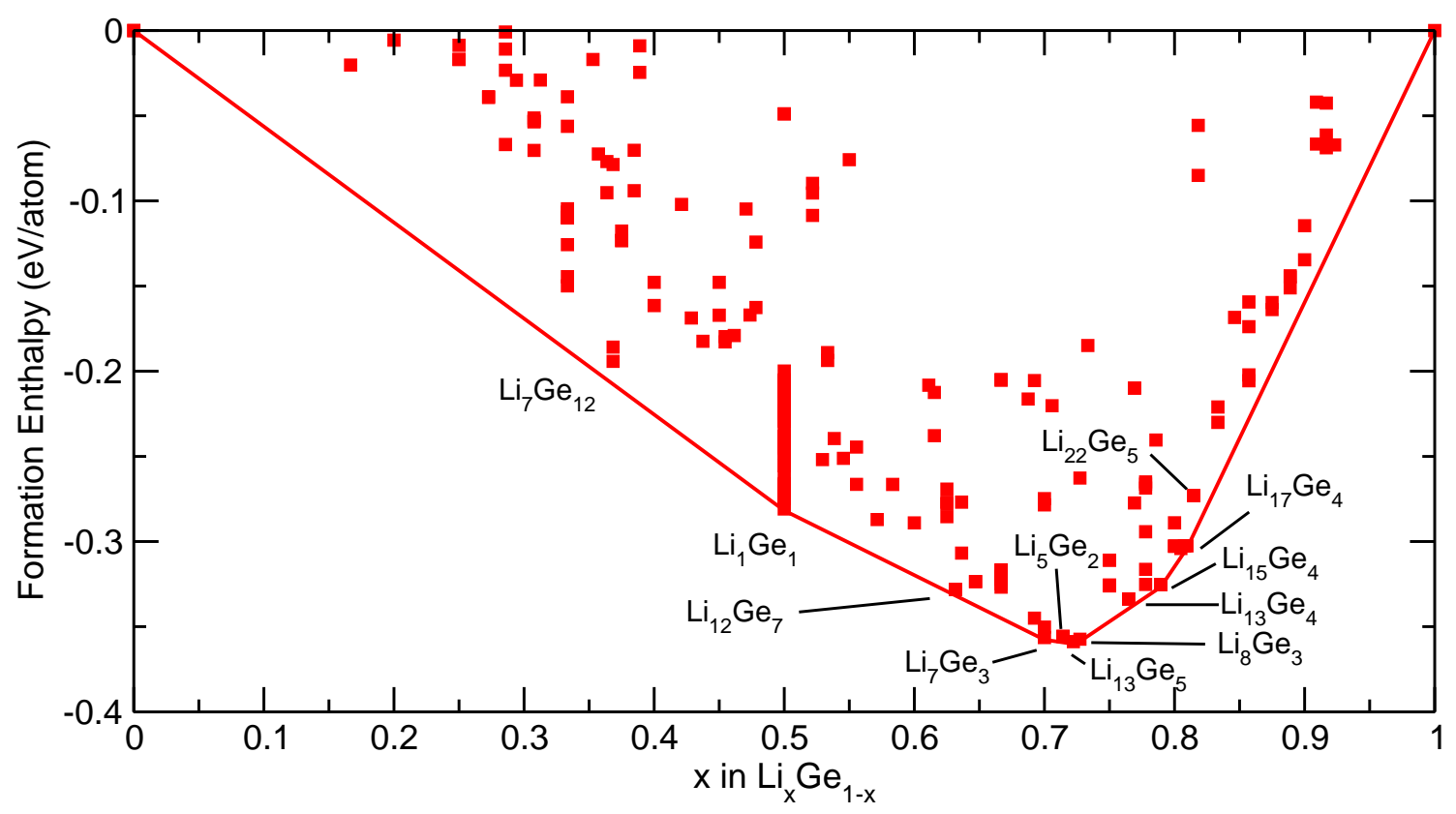

FIG. 4: (Color online) The Li-Ge binary composition diagram. The red squares indicate the formation enthalpy of a structure. The red line is the tie-line indicating the stable structures at $0 \mathrm{~K}$ predicted by DFT.

$\mathrm{Li}_{1} \mathrm{Ge}_{1}$ has an $I 4_{1} / a^{67}$ ground state and a $I 4_{1} / a m d^{68}$ high pressure form. DFT predicts $I 4_{1} /$ amd and a new layered $P 4 / \mathrm{mmm}$ phase $\sim 0.012 \mathrm{eV} /$ f.u. and $\sim 0.020 \mathrm{eV} /$ f.u. above the $I 4_{1} / a$ ground state respectively. The $P 4 / \mathrm{mmm}$ phase is isostructural with the Li-Si phase discussed above in Sec.IVA DFT predicts that the system undergoes a phase transition from the $I 4_{1} /$ amd to the $P 4 / \mathrm{mmm}$ phase at $5 \mathrm{GPa}$.

Grüttner et al. mentioned a $\mathrm{Li}_{12} \mathrm{Ge}_{7}$ phase isotypic with the corresponding $\mathrm{Li}_{12} \mathrm{Si}_{7}$ phase ${ }^{22}$ in a very brief report, but did not present any further data to support its discovery. DFT also predicts a $\mathrm{Li}_{12} \mathrm{Ge}_{7}$ Pnma phase near the tie-line.

$\mathrm{Li}_{11} \mathrm{Ge}_{6}$ was synthesized by Frank et al. ${ }^{25}$ with a molecular volume of $172.3 \mathrm{~cm}^{3} \mathrm{~mol}^{-1}$. Nesper et al. 62 claim that the phase is actually $\mathrm{Li}_{8} \mathrm{MgGe}_{6}$, suggesting that since $\mathrm{Li}_{8} \mathrm{MgGe}_{6}$ has a molecular volume of $166.5 \mathrm{~cm}^{3} \mathrm{~mol}^{-1}$ it is unlikely that $\mathrm{Li}_{11} \mathrm{Ge}_{6}$ could have two more atoms per formula unit ${ }^{73}$ DFT also finds a $\mathrm{Li}_{11} \mathrm{Ge}_{6} \mathrm{Cmcm}$ phase slightly above the tie-line with a volume of $286.26 \AA^{3}$ per f.u., which corresponds to a molecular volume of $172.4 \mathrm{~cm}^{3} \mathrm{~mol}^{-1}$. Hence it seems entirely possible to us that $\mathrm{Li}_{11} \mathrm{Ge}_{6} \mathrm{Cmcm}$ was synthesized by Frank et al. as initially proposed.

$\mathrm{Li}_{9} \mathrm{Ge}_{4}$ in the $\mathrm{Cmcm}$ symmetry group, have been made electrochemically and from high temperature fusion, 27,28,58 but all of our calculations show it well above the tie line, favoring disproportion into a $P 32_{1} 2 \mathrm{Li}_{7} \mathrm{Ge}_{3}$ phase. $\mathrm{Li}_{7} \mathrm{Ge}_{3}$ with $P 32_{1} 2$ symmetry was first mentioned by ref.22 but no supporting information was given. Jain et al. found an unknown phase that they suggested was $\mathrm{Li}_{7} \mathrm{Ge}_{3}$ fitting the diffraction data to $R \overline{3} m$ symmetry. ${ }^{27}$ Hence we suggest that Jain et al. synthesized either the $\mathrm{Li}_{5} \mathrm{Ge}_{2}$ or indeed $\mathrm{Li}_{8} \mathrm{Ge}_{3}$ phases, DFT predicting that both phases have the $R \overline{3} m$ symmetry. $\mathrm{Li}_{5} \mathrm{Ge}_{2}$ is above the tie-line and $\mathrm{Li}_{13} \mathrm{Ge}_{5}$ and $\mathrm{Li}_{8} \mathrm{Ge}_{3}$ are all stable although to the best of our knowledge they have not previously been presented in the literature. This may be due to thermal effects, see the discussion of similar arguments for $\mathrm{Li}_{5} \mathrm{Si}_{2}$ in $\mathrm{Sec}$.IVB $\mathrm{Li}_{16} \mathrm{Ge}_{5}$ was predicted by St. John, et al. .65 during electrochemical studies. They presented no crystal structure nor is there any prototype structure of $\{\mathrm{Li} / \mathrm{Na}\}\{\mathrm{Si} / \mathrm{Ge} / \mathrm{Sn} / \mathrm{Pb}\}$ with this stoichiometry. DFT predicts a $\mathrm{Li}_{13} \mathrm{Ge}_{4}$ Pbam phase, isostructural with the $\mathrm{Li}_{13} \mathrm{Si}_{4}$ phase which is slightly above the tie-line and with a similar $\mathrm{Li}: \mathrm{Si}$ ratio to $\mathrm{Li}_{16} \mathrm{Ge}_{5}$. Recently preliminary results by $\mathrm{H}$. Jung et al ${ }^{63}$ have produced electrochemically new phases in the $\mathrm{Li}_{2.33} \mathrm{Ge}-\mathrm{Li}_{3.5} \mathrm{Ge}$ range whose $\mathrm{X}$-ray pair distribution functions (PDF) match at least one of our predicted phases. A fuller investigation will be presented later.

The $\mathrm{Li}_{7} \mathrm{Ge}_{2}$ phase with $\mathrm{Cmmm}$ symmetry can be made electrochemically and by annealing from high temperature melt. $\frac{28,58}{}$ DFT-GGA predicts the $P \overline{3} m 1$ phase above the tieline and $0.08 \mathrm{eV} / \mathrm{f}$.u more stable than the $\mathrm{Cmmm}$ phase. This discrepancy remains after using harder pseudopotentials and either the LDA exchange-correlation or the HSE06 hybrid functional ${ }^{69} \mathrm{~A}$ fuller investigation into this will be presented elsewhere.

We find the well known $\mathrm{Li}_{15} \mathrm{Ge}_{4}$ stoichiometry $I \overline{4} 3 d$ phase stable ${ }^{27,28,30,31}$ The most lithiated phase has been a matter of debate in all Li-Group 4 compounds including germanium. Its stoichiometry was reported as $\mathrm{Li}_{22} \mathrm{Ge}_{5}$ with $F 23$ symmetry, ${ }^{33}$ due to its similarity to $\mathrm{Li}_{22} \mathrm{~Pb}_{4}{ }^{70}$ More recently, Goward et $a l .{ }^{32}$ studied this family of structures and show that for the $\mathrm{Ge}$, $\mathrm{Sn}$ and $\mathrm{Pb}$ compounds the correct stoichiometry is $\mathrm{Li}_{17} \mathrm{Ge}_{4}$ with $F \overline{4} 3 m$ symmetry. $F \overline{4} 3 m$ symmetry $\mathrm{Li}_{21} \mathrm{Ge}_{5}, \mathrm{Li}_{22} \mathrm{Ge}_{5}$ and $\mathrm{Li}_{17} \mathrm{Ge}_{4}$ are found by DFT all at local energy minima. However, $\mathrm{Li}_{17} \mathrm{Ge}_{4}$ is on the tie-line. Fassler et al.also predict a $\mathrm{Li}_{4.10} \mathrm{Ge}$ phase analogous to the $\mathrm{Li}_{4.11} \mathrm{Si}$ phase. We use the same model structures as in the $\mathrm{Li}_{4.11} \mathrm{Si}$ phase for our DFT 
TABLE III: Experimental and predicted phases of $\mathrm{Li}_{\mathrm{x}} \mathrm{Ge}$ system.

\begin{tabular}{lccc}
\hline \hline Experimental Symmetry & $\mathrm{x}$ & Stoichiometry & Predicted Symmetry \\
\hline$F d \overline{3} m^{a}$ & 0.000 & $\mathrm{Ge}$ & $F d \overline{3} m$ \\
$P m n 2_{1}{ }^{b}, P 2 / n^{c}$ & 0.580 & $\mathrm{Li}_{7} \mathrm{Ge}_{12}$ & $P c$ \\
$I 4_{1} / a^{d}, I 4_{1} / a m d^{*, e}$ & 1.000 & $\mathrm{Li}_{1} \mathrm{Ge}_{1}$ & $I 4_{1} / a, I 4_{1} / a m d^{*}, P 4 / m m m^{* *}$ \\
$P n m a^{f}$ & 1.710 & $\mathrm{Li}_{12} \mathrm{Ge}_{7}$ & $P n m a^{*}$ \\
$C m c m^{g}$ & 1.83 & $\mathrm{Li}_{11} \mathrm{Ge}_{6}$ & $C m c m^{*}$ \\
$C m c m^{h, i, j}$ & 2.25 & $\mathrm{Li}_{9} \mathrm{Ge}_{4}$ & $C m c m^{*}$ \\
$P 32_{1} 2^{f}, R \overline{3} m^{i}$ & 2.33 & $\mathrm{Li}_{7} \mathrm{Ge}_{3}$ & $P 32_{1} 2, P 21 / m^{*}$ \\
& 2.50 & $\mathrm{Li}_{5} \mathrm{Ge}_{2}$ & $R \overline{3} m^{*}$ \\
& 2.60 & $\mathrm{Li}_{13} \mathrm{Ge}_{5}$ & $P \overline{3} m 1$ \\
$l$ & 2.67 & $\mathrm{Li}_{8} \mathrm{Ge}_{3}$ & $R \overline{3} m$ \\
& 3.20 & $\mathrm{Li}_{16} \mathrm{Ge}_{5}$ & \\
$C m m m^{m, j}$ & 3.25 & $\mathrm{Li}_{13} \mathrm{Ge}_{4}$ & $P b a m^{*}$ \\
$I \overline{4} 3 d^{n, i, j}$ & 3.50 & $\mathrm{Li}_{7} \mathrm{Ge}_{2}$ & $P \overline{3} m 1^{*}, C m m m^{* *}$ \\
$F \overline{4} 3 m^{o}$ & 3.75 & $\mathrm{Li}_{15} \mathrm{Ge}_{4}$ & $I \overline{4} 3 d$ \\
$F \overline{4} 3 m^{p, j, q}$ & 4.20 & $\mathrm{Li}_{17} \mathrm{Ge}_{4}$ & $F \overline{4} 3 m$ \\
$P 6_{3} / m m c^{r}$ & 4.25 & $\mathrm{Li}_{22} \mathrm{Ge}_{5}$ & $F \overline{4} 3 m^{*}$ \\
\hline \hline
\end{tabular}

Sangster and Pelton's work was invaluable for an overview of the field 58

* First metastable above tie-line.

** Second metastable above tie-line.

${ }^{a}$ A. W. Hul159.

${ }^{b}$ Very brief summaries are given by Grüttner et al ${ }^{22,60}$

${ }^{c}$ Kiefer and Fässler 61

${ }^{d}$ E. Menges et al. 23

e J. Evers, et al. 24

${ }^{f}$ Reported in abstract by Grüttner et al.$^{22}$

${ }^{g}$ First found by Frank et al ${ }^{25}$; Nesper et al ${ }^{62}$ suggested it is actually $\mathrm{Li}_{8} \mathrm{MgGe}_{6}$.

${ }^{h}$ V. Hopf et al. 26

${ }^{i}$ Jain et al $\stackrel{27}{{ }^{2}}$

$j$ Yoon et al. 28

${ }^{l}$ E. M. Pell finds $\mathrm{Li}_{3} \mathrm{Ge}_{1},{ }^{64}$ See Sangster et al. ${ }^{a}$ and a discussion therein. St. John et al. report that they have found the $\mathrm{Li}_{3} \mathrm{Ge}_{1} \mathrm{reported}$ earlier as $\mathrm{Li}_{16} \mathrm{Ge}_{5}{ }^{65}$

${ }^{m}$ V. Hopf et al. 29

${ }^{n}$ Gladyshevskii et al ${ }^{30}$ and Johnson et al ${ }^{31}$

${ }^{o}$ Goward et al ${ }^{32}$

${ }^{p}$ Gladyshevskii et al ${ }^{33}$

${ }^{q}$ Reported by Jain et al ${ }^{27}$ as $\mathrm{Li}_{21.1875} \mathrm{Ge}_{5}$

${ }^{r}$ C. .S. Barrett ${ }^{66}$

TABLE IV: Low energy $\mathrm{Li}_{1} \mathrm{Ge}_{1}$ metastable phases, with formation energy, $E_{f}$ p.f.u relative to that of the energy of the ground state. The structures are isotypic of those found in $\mathrm{Li}_{1} \mathrm{Si}_{1}$, as shown in Table 1 and Fig. 2 DFT predicts that the P4/mmm phase is the most stable above $5 \mathrm{GPa}$.

\begin{tabular}{cccc}
\hline \hline $\begin{array}{c}\mathrm{E}_{f} \\
\text { (eV/f.u.) }\end{array}$ & Symmetry & $\begin{array}{c}\text { Volume } \\
\left(\AA^{3} / \text { f.u. }\right)\end{array}$ & Description \\
\hline 0.00 & $I 4_{1} / a$ & 35.1 & Li tetrahedra in a 3-fold coordinated Ge network \\
0.01 & $I 41 /$ amd & 32.2 & Known high pressure phase \\
0.02 & $P 4 / m m m$ & 31.9 & Flat Ge sheets 4 membered rings \\
0.03 & $R \overline{3}$ & 36.8 & Distorted Li octahedra 3-fold coordinated Ge network \\
0.04 & $P 2 / m$ & 32.1 & Isostructural with the corresponding $\mathrm{Li}_{1} \mathrm{Sn}_{1}$ phase \\
\hline \hline
\end{tabular}

calculations. These are above the tie-line as is expected for a high-temperature phase.

The Li-Ge system has an analogous inclination to forming $\mathrm{Ge}-\mathrm{Ge}$ dumbbells as in $\mathrm{Li}-\mathrm{Si}$, as discussed in Sec.IVD

\section{DISCUSSION}

Crystal structures of the Li-Si and Li-Ge systems have been presented, found using both AIRSS searches and atomic species swapping of ICSD structures. Below we discuss the 


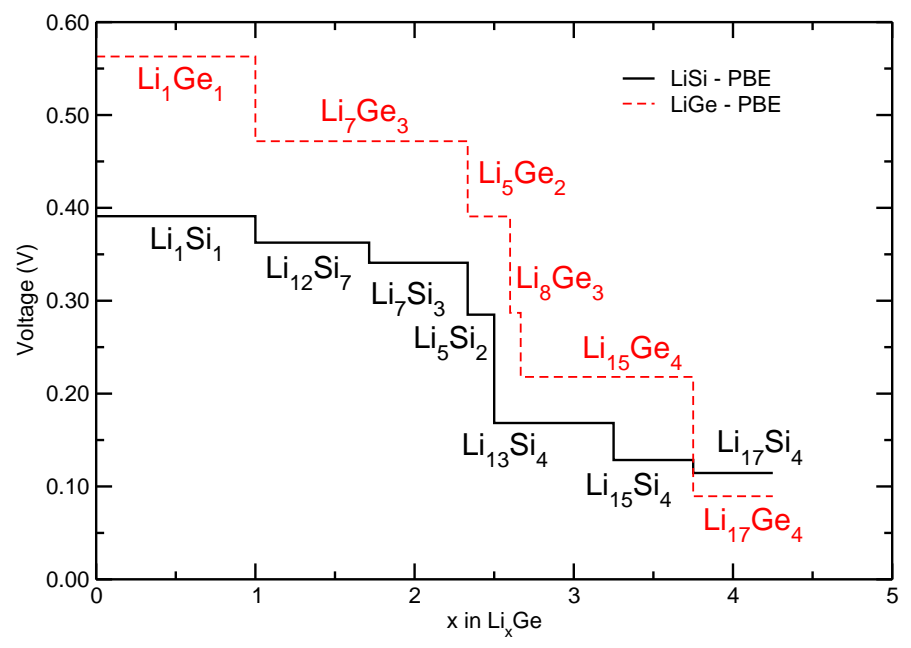

FIG. 5: (Color online) Potential-composition curves of stable structure found on the $\mathrm{Li}-\mathrm{Si}$ and $\mathrm{Li}-\mathrm{Ge}$ convex hull diagrams. The $\mathrm{Li}-\mathrm{Ge}$ results are at a higher average voltage.

structures that are likely to be thermally accessible at room temperature, that is, those at a local minima on the DFT potential energy surface which reside on, or close to, the convex hull. These structures serve as a model for the clustering and bonding behavior of electrochemically lithiated silicon and germanium $\underline{\underline{71}}$

The Li-Si system was used to validate our method: DFT finds all of the known phases as local energy minima including independently uncovering the $\mathrm{Li}_{17} \mathrm{Si}_{4}$ phase. For the $\mathrm{Li}$ Ge system, DFT finds $\mathrm{Li}_{5} \mathrm{Ge}_{2}, \mathrm{Li}_{8} \mathrm{Ge}_{3}, \mathrm{Li}_{13} \mathrm{Ge}_{5}$ and $\mathrm{Li}_{13} \mathrm{Ge}_{4}$ locally stable and, to the best of our knowledge, these have not been presented in the literature before. DFT predicts that $\mathrm{Li}_{7} \mathrm{Ge}_{12}$ and $\mathrm{Li}_{11} \mathrm{Ge}_{6}$ are local energy minima; the former having $P c$ symmetry and the latter $C m c m$. It was reported that $\mathrm{Li}_{11} \mathrm{Ge}_{6}$ may be produced from a high-temperature melt ${ }^{25}$ but this has been disputed. ${ }^{62}$ Also at local energy minima are the $\mathrm{Li}_{12} \mathrm{Ge}_{7}$ Pnma and $\mathrm{Li}_{7} \mathrm{Ge}_{3} P 32_{1} 2$ phases, which were suggested by Grüttner ${ }^{22}$ but without presenting the crystal structure. An unknown phase was found by heating ball milled Li-Ge, its XRD pattern fits an $\mathrm{Li}_{7} \mathrm{Ge}_{3}$ phase with $R \overline{3} m$ symmetry. Since DFT and Grüttner both predict $\mathrm{Li}_{7} \mathrm{Ge}_{3}$ has $P 32_{1} 2$ symmetry, we propose that the unknown phase may be either the $\mathrm{Li}_{5} \mathrm{Ge}_{2}$ or $\mathrm{Li}_{8} \mathrm{Ge}_{3}$ phases which have a similar stoichiometry to $\mathrm{Li}_{7} \mathrm{Ge}_{3}$ and both of which DFT predicts to have $R \overline{3} \mathrm{~m}$ symmetry.

For the $\mathrm{Li}-\mathrm{Si}$ and $\mathrm{Li}-\mathrm{Ge}$ structures on the tie-lines, the average voltages were calculated relative to lithium metal. This included for the first time $\mathrm{Li}_{17} \mathrm{Si}_{4}$ and $\mathrm{Li}_{1} \mathrm{Si}_{1}$. The average voltages are in good agreement with both previous calculations and experiment. They are higher in $\mathrm{Li}-\mathrm{Ge}$ than $\mathrm{Li}-\mathrm{Si}$, implying that germanium has a lower energy density than silicon. However the higher insertion voltage is safer during lithiation, reducing the chance of lithium plating which can result in dendrites short circuiting the cell. Lithium in germanium also has higher diffusivity than in silicon.

$\mathrm{Li}_{1} \mathrm{Si}_{1}$ was previously only synthesisable at high pressure but has recently been synthesized by highly energetic ball milling, remotivating interest in the high-pressure phases. AIRSS searches predict a selection of higher energy $\mathrm{Li}_{1} \mathrm{Si}_{1}$ and $\mathrm{Li}_{1} \mathrm{Ge}_{1}$ phases. At lower pressures threedimensional three-fold coordinated silicon/germanium networks were prevalent. However, at higher densities, both silicon and germanium exhibited a $P 4 / \mathrm{mmm}$ structure comprising flat sheets of four-fold coordinated silicon and germanium atoms respectively. These became the most stable phase of $\mathrm{Li}_{1} \mathrm{Si}_{1}$ and $\mathrm{Li}_{1} \mathrm{Ge}_{1}$ at $2.5 \mathrm{GPa}$ and $5 \mathrm{GPa}$ respectively. Given the interest in silicene our layered compounds might provide an alternative route to layered silicon.

A LIB does not necessarily have time to equilibrate thermodynamically over large length scales $\underline{\underline{6}}$ The ability to generate a wide range of locally-stable low-energy structures above the ground state allows us to visualize the types of clusters which form in the LIB during cycling. Over a lithiation range of $\mathrm{Li}_{x} \mathrm{Si}, x=2.33-3.25$ we found that the structures present exhibited Si-Si dumbbells. At higher lithiation all of the silicon dumbbells break up and the crystalline $\mathrm{Li}_{15} \mathrm{Si}_{4}$ phase forms. Since these dumbbells were seen in both ground state and metastable phases is seems likely that they will exist in LIB anodes, probably in a lower symmetry solid solution. Furthermore we find the analogous dumbbell containing structures in the Li-Ge system.

Above we have demonstrated that the combination of both atomic species swapping the ICSD phases and AIRSS is a powerful tool for predicting the crystal structures of LIB electrode materials. A refinement to the method combines these two techniques by using results of the AIRSS searches as inputs to the species swapping technique. For example, the low-energy structures found by AIRSS in $\mathrm{Li}_{1} \mathrm{Si}_{1}$ were reoptimized as candidate $\mathrm{Li}_{1} \mathrm{Ge}_{1}$ phases in the Li-Ge system.

Our method has only provided results of the stable and metastable structures at $0 \mathrm{~K}$, of course, the effect of temperature could be included post hoc using phonon calculations within the harmonic approximation and beyond. Our method serves as a crucial first step in ab initio materials discovery and design.

\section{Acknowledgments}

The authors would like to thank Edgar Engel for useful discussions and Hyeyoung Jung, Yan-Yan Hu and Phoebe K. Allan for sharing their preliminary results and useful discussions. AJM acknowledges the support from the Winton Programme for the Physics of Sustainability. This work was supported by the Engineering and Physical Sciences Research Council (EPSRC) of the U.K. Computational resources were provided by the University College London Research Computing service and the Cambridge High Performance Computing service. 
1 S. Chu and A. Majumdar, Nature 488, 294 (2012).

2 S. Lai, J. Electrochem. Soc. 123, 1196 (1976).

3 C. J. Wen and R. A. Huggins, J. Sol. Stat. Chem. 37, 271 (1981).

4 W. J. Weydanz, M. Wohlfahrt-Mehrens and R. A. Huggins, J. Power Sources 81-82, 237 (1999).

5 J. P. Maranchi, A. F. Hepp and P. N. Kumta, Electrochem. and Solid-State Lett. 6, A198 (2003). P. Limthongkul, Y.-I. Jang, N. J. Dudney and Y.-M. Chiang, J. Power Sources 119-121, 604 (2003). P. Limthongkul, Y.-I. Jang, N. J. Dudney and Y.-M. Chiang, Acta Mater. 51, 1103 (2003).

6 B. Key, R. Bhattacharyya, M. Morcrette, V. Seznéc, J.-M. Tarascon, and C. P. Grey, J. Am. Chem. Soc. 131, 9239, (2009).

7 J. Li and J. R. Dahn, J. Electrochem. Soc. 154, A156 (2007).

8 Kwon, J. H. Ryu and S. M. Oh, Electrochi,. Acta 55, 8051, (2010).

9 M. N. Obrovac, L. J. Krause, J. Electrochem. Soc. 154, A103 (2007).

10 T. D. Hatchard and J. R. Dahn, J. Electrochem. Soc. 151, A838 (2004).

11 M. N. Obrovac and L. Christensen, Electrochem. and Solid-State Lett. 7, A93 (2004).

12 Y.-M. Kang, S.-B Suh, and Y.-S. Kim, Inorg. Chem. 48, 11631 (2009).

13 B. Key, M. Morcrette, J.-M. Tarascon, and C. P. Grey, J. Am. Chem. Soc. 133, 503, (2011).

14 T. K.-J. Köster, E. Salager, A. J. Morris, B. Key, V. Seznec, M. Morcrette, C. J. Pickard and C. P. Grey, Angew. Chem. Int. Ed. 123, 12799 (2011).

15 V. L. Chevrier and J. R. Dahn, J. Electrochem. Soc. 157, A392A398 (2010).

16 V. L. Chevrier and J. R. Dahn, J. Electrochem. Soc. 156, A454A458 (2009).

17 V. L. Chevrier, J. Zwanziger and J. R. Dahn, J. Alloy Compd. 496, 25-36 (2010).

18 M. Zeilinger, I. .M. Kurylyshyn, U. Häussermann and T. F. Fässler, Chem. Mater. 25, 1960 (2013).

19 H. Okamoto, J. Phase Equilib. Diffus. 30, 118, (2009).

${ }^{20}$ M. Zeilinger, I. .M. Kurylyshyn, U. Häussermann and T. F. Fässler, Chem. Mater. 2013 published online (dx.doi.org/10.1021/cm4029885).

21 C.-M. Park and J.-H. Kim and H. Kim and H.-J. Sohn,39 3115, (2010). Chem. Soc. Rev.

22 A. Grüttner, R. Nesper, and H. G. von Schnering, Acta. Crystallog. A 37, Supl. C161 (1981).

23 E. Menges, V. Hopf, H. Schäfer and A. Weiss, Z. Naturforsh B, 24, 1351, (1969).

24 J. Evers, G. Oehlinger, G. Sextl and H.-O. Becker, Angew. Chem. Int. Ed. 26 76, (1987).

25 U. Frank and W. Müller Z. Naturforsch. B, 30B, 313, (1975).

26 V. Hopf, H. Schäfer and A. Weiss, Z. Naturforsh B, 25, 653, (1970).

27 A. Jain, E. Kawasako, H. Miyaoka, T. Ma, S. Isobe, T. Ichikawa and Y. Kojima, J. Phys. Chem. C 117, 5650 (2013).

28 S. Yoon, C.-M. Park, and H.-J. Sohn, Electrochem. and Sol. Stat. Lett. 11, A42 (2008).

29 V. Hopf, W. Müller and H. Schäfer, Z. Naturforsh B, 27, 1157, (1972).

30 E. L. Gladyshevskii and P. I. Kripyakevich, Sov. Phys.-Cryst., 5, 549 (1961).

31 Q. Johnson, G. S. Smith and D. Wood, Acta Cryst. 18, 131, (1965).
32 G. R. Goward, N. J. Taylor, D. C. S. Souza and L. F. Nazar, J. Alloy Comp 329. 1-2, 82, (2001)

33 E. L. Gladyshevskii, G. I. Oleksiv and P. I. Kripyakevich, Sov. Phys.-Cryst., 9, 269 (1964).

34 C. J. Pickard and R. J. Needs, Phys. Rev. Lett. 97, 045504 (2006).

35 C. J. Pickard and R. J. Needs, J. Phys.: Condens. Matter 23, 053201 (2011).

36 A. S. Ivanov, A. J. Morris, K. V. Bozhenko, C. J. Pickard and A. I. Boldyrev, Angew. Chem. Int. Ed. 51, 8330 (2012).

37 J. Mulroue, A. J. Morris, and D. M. Duffy, Phys. Rev. B. 84, 094118 (2011).

38 J. Mulroue, M. Watkins, A. J. Morris, and D. Duffy, J. Nucl. Mat. 437, 1-3, 261 (2013).

39 A. J. Morris, C. J. Pickard and R. J. Needs, Phys. Rev. B 78, 184102 (2008).

40 A. J. Morris, C. J. Pickard and R. J. Needs, Phys. Rev. B 80, 144112 (2009).

41 A. J. Morris, C. P. Grey, R. J. Needs and C. J. Pickard, Phys. Rev. B 84, 224106 (2011).

42 A. J. Morris, R. J. Needs, E. Salager, C. P. Grey and C. J. Pickard, Phys. Rev. B 87, 174108, (2013).

43 S. J. Clark et al., Z. Kristallogr. 220, 567 (2005).

44 M. K. Aydinol, A. F. Kohan, G. Ceder, K. Cho and J. Joannopoulos, Phys. Rev. B, 56, 1354, (1997).

45 V. L. Chevrier, J. W. Zwanziger and J. R. Dahn, Can. J. Phys. 87, 625, (2009).

46 I. A. Courtney, J. S. Tse, O. Mao, J. Hafner and J. R. Dahn, Phys. Rev. B, 58, 15583 (1998).

47 W. W. Tipton, C. R. Bealing, K Mathew and R. G. Hennig, Phys. Rev. B, 87, 184114 (2013).

48 L .A. Stearns, J. Gryko, J. Diefenbacher, G. K. Ramachandran, and P. F. McMillan, J. Sol. Stat. Chem. 173, 251, (2003).

49 Y. Kubota, M. C. S. Escaño, H. Nakanishi and H. Kasai, J. Alloys Comp. 458151 (2008).

50 Wan Si Tang, Jean-Noël Chotard and Raphaël Janot, J. Electrochem. Soc. 160 A1232 (2013).

51 R. Nesper, H. G. von Schnering and J. Curda, Chem. Ber. 119, 3576 (1986).

52 Y. Kubota, M. C. S. Escaño, H. Nakanishi and H. Kasai, J. App. Phys. 102 053704, (2007).

53 H.-G. von Schnering, R. Nesper, K.-F. Tebbe and J. Curda, Z. Metallkde.71, 357, (1980).

54 I. Barvík, Czech. J. Phys. B 33 (1983).

55 R. Nesper and H. .G. von Schnering, J. Sol. Stat. Chem 70, 48, (1987).

56 K. Cenzual, M. N. Gelato, M. Penzo and E. Parthe, Z. Kristallog. 193, 217, (1990).

57 U. Frank and W. Müller, Z. Naturfor. B. 30, 316, (1975).

58 J. Sangster and A. D. Pelton, J. Phase Equilib. 18289 (1997).

59 A. W. Hull, Phys. Rev. 20, (Minutes of the Washington Meeting), 113, (1922).

60 A. Grüttner, R. Nesper, and H. G. von Schnering, Agnew. Chem. Int. Ed. 21, 12, 912 (1982).

61 F. Kiefer and T. F. Fässler Sol. State. Sci. 13, 636, (2011).

62 R. Nesper, J. Curda and H. G. von Schnering, J. Sol. Stat. Chem. 62, 199, (1986).

63 H. Jung, Y.-Y. Yau, P. .K. Allen and C. P. Grey.

64 E. M. Pell, J. Phys. Chem. Solids 3, 74, (1957).

65 M. .R. St. John, A. J. Furgala and A. F. Sammells, J. Electrochem. Soc. 129, 247, (1982).

66 C. .S. Barret, Phys. Rev. 72 245, (1947) 
67 E. Menges. V. Hopf, H. Schaefer and A. Weiss, Z. Natur. B 27, 313, (1975).

68 J. Evers, G. Oehlinger, G. Sextl and H. O. Becker, Angew. Chem. (Ger. Ed) 99, 69, (1987).

69 A. V. Krukau, O. A. Vydrov, A. F. Izmaylov and G. E. Scuseria, J. Chem. Phys. 125, 224106 (2006)

70 A. Zalkin and W. J. Ramsey, J. Phys. Chem. 62, 689, (1958).

71 K. Ogata, E. Salager, C. J. Kerr, A. E. Fraser, C. Ducati, A. J. Mor- ris, S. Hofmann and C. P. Grey Nature Comm. 5, 3217, (2014).

72 Since the $\mathrm{Li}_{16.5} \mathrm{Si}_{4}$ model contains partially occupied $\mathrm{Li}$ sites we extended the cell in the $a$ direction fully occupying four $8 \mathrm{~g}$ and two 4c sites before optimizing the geometry using DFT.

73 Confusingly Sangster and Pelton ${ }^{58}$ report that Nesper et al. claim it is the $\mathrm{Li}_{8} \mathrm{MgSi}_{6}$ phase. 